\title{
PERENCANAAN DISTRIBUSI TEH BOTOL SOSRO DENGAN MENGGUNAKAN METODE DISTRIBUTION REQUIREMENT PLANNING (DRP) DAN SAVING MATRIX UNTUK EFISIENSI BIAYA DISTRIBUSI DI PT. SINAR SOSRO
}

\author{
Amri Ismail, Fatimah dan Arif Agung Permana \\ Jurusan Teknik Industri, Fakultas Teknik, Universitas Malikussaleh, Aceh-Indonesia \\ ${ }^{*}$ Corresponding Author: iramri@unimal.ac.id
}

\begin{abstract}
Abstrak - PT. Sinar Sosro Deli Serdang adalah perusahaan yang bergerak dalam bidang pengolahan minuman. PT. Sinar Sosro memproduksi 25 jenis produk minuman antara lain Teh Botol Sosro, Fruit Tea dan S-Tee dalam berbagai varian rasa dan kemasan. Penentuan pengiriman ke Distribusi Center (DC) umumnya dilakukan berdasarkan pada taksiran pengalaman ataupun permintaan langsung oleh DC tanpa memperhatikan jumlah stock dan ketersediaan sumber daya yang lain seperti transportasi dan biaya. Dalam menyelesaikan permasalahan perusahaan maka dilakukan penelitian untuk memperkirakan permintaan Distribusi Center, distribusi produk dengan menggunakan metode Distribution Requirement Planning (DRP), dan saving matrix. Ketiga metode ini digunakan dengan tujuan untuk pemghematan biaya distribusi dalam proses pengiriman menuju Distribution Center. Biaya yang dikeluarkan oleh perusahaan adalah sebesar Rp.18.239.683,20 sedangkan dengan menggunakan metode DRP biaya yang dikeluarkan adalah sebesar Rp 14.319.564. Penerapan metode ini dapat menghasilkan efisiensi biaya sebesar $31,79 \%$. Adapun jarak awal yang ditempuh oleh perusahaan adalah $214,2 \mathrm{~km}$, sedangkan rute usulan dengan menggunakan metode saving matrix 146,1 km. Penerapan rute usulan ini dapat menghasilkan efisiensi jarak sebesar $31,79 \%$.
\end{abstract}

Kata Kunci: Distribution Requirement Planning (DRP), Saving Matrix, Minimasi Biaya Distribusi.

\section{Pendahuluan}

\subsection{Latar belakang}

Perkembangan dunia industri mengalami persaingan yang ketat dalam era industri sekarang ini, baik yang bergerak dalam produksi barang maupun pendistribusian barang. Distributor dituntut untuk menghasilkan produk yang berkualitas tinggi. Hal ini menyebabkan distributor melakukan berbagai cara untuk meningkatkan kepuasan pelanggan. Konsumen akan merasa puas terhadap pelayanan distributor akan pengiriman produk yang tepat jumlah dan tepat waktu. Hal ini menuntut distributor untuk mengendalikan persediaan produk dalam gudang, memenuhi permintaan konsumen sesuai dengan kebutuhannya, serta mengatur penjadwalan agar dapat meminimumkan biaya yang tidak diperlukan untuk mengurangi biaya produksi dengan cara mengoptimumkan proses distribusi produk yang dihasilkan. Kurang baiknya perencanaan sistem distribusi akan mengarah pada pemborosan biaya transportasi dan penurunan kepuasan konsumen yang selanjutnya menyebabkan hilangnya kepercayaan.

PT. Sinar Sosro berada di Jl. Raya Medan Tanjung Morawa, Kabupaten Deli Serdang adalah perusahaan yang bergerak dalam bidang pengolahan minuman. Salah satu produknya adalah teh botol sosro kemasan botol plastik yang disimpan dan dijual dalam satuan carton (CRT). Carton (CRT) merupakan satuan produk dipacking dengan kardus. Isi setiap kardus terdiri 12 botol produk kemasan botol plastik.

Produk teh botol sosro kemasan botol plastik adalah produk memilki jumlah permintaan (demand) paling banyak yaitu sebesar 6.930 carton selama 8 minggu. Penentuan pengiriman ke Distribusi Center (DC) umumnya dilakukan berdasarkan pada taksiran pengalaman ataupun permintaan langsung oleh DC 
tanpa memperhatikan jumlah stock dan ketersediaan sumber daya yang lain seperti transportasi dan biaya. Hal ini menyebabkan pengiriman produk dan biaya yang dikeluarkan kurang efektif.

Peramalan akan memprediksi jumlah permintaan atau jumlah produk yang harus diproduksi dimasa yang akan datang sehingga dengan melakukan proses peramalan, perusahaan akan dapat memperkirakan inventori yang harus dilakukan di masa depan. Peramalan akan meminimalisir terjadinya kekurangan atau kelebihan inventori yang akan menyebabkan kerugian di perusahaan. Oleh karena itu perlu dilakukan penerapan metode permalan dan DRP dalam memenuhi kebutuhan DC agar pengiriman produk menjadi optimal dan dapat meminimalkan biaya distribusi.

\section{Tinjauan Pustaka}

\subsection{Peramalan}

Peramalan (forecasting) adalah seni dan ilmu untuk memperkirakan kejadian dimasa depan. Hal ini dapat dilakukan dengan melibatkan pengambilan data masa lalu dan menempatkannya kemasa yang akan datang dengan suatu bentuk model matematis [4.

Metode-metode peramalan dengan menggunakan analisa pola hubungan antara variable yang akan diperkirakan dengan variabel waktu, atau analisa deret waktu, terdiri dari [2]

1. Metode pemulusan (smoothing)

Metode smoothing adalah metode peramalan dengan mengadakan penghalusan terhadap data pada masa lalu, yaitu dengan mengambil rata-rata dari nilai beberapa tahun untuk menaksir nilai pada beberapa tahun kedepan. Secara umum metode smoothing diklasifikasikan menjadi dua bagian, yaitu [2] :

a. Metode Rata-rata, yang terdiri dari:

1. Rata-rata Bergerak Tunggal (Single Moving Average).

2. Rata-rata Bergerak Ganda (Double Moving Average.

3. Kombinasi Rata-rata bergerak lainnya.

b. Metode Pemulusan Eksponensial.

2. Metode Box Jenkis

Metode Box Jenkis menggunakan dasar deret waktu dengan model matematis, agar kesalahan yang terjadi dapat sekecil mungkin yang membutuhkan identifikasi model estimasi parameternya. Jarang dipakai, namun baik untuk ramalan jangka panjang, menengah, dan jangka pendek.

3. Metode proyeksi trend dengan regresi.

Metode proyeksi trend dengan regresi, merupakan dasar garis trend untuksuatu persamaan matematik, sehingga dengan dasar persamaan tersebut dapat diproyeksikan hal yang diteliti untuk masa depan.

Metode saving matriks pada hakekatnya adalah metode untuk meminimumkan jarak atau waktu atau ongkos dengan mempertimbangkan kendala-kendala yang ada. Karena disini kita berbicara koordinat tujuan pengiriman maka masuk akal untuk menggunakan jarak sebagai fungsi tujuan. Artinya, kita akan meminimumkan jarak yang ditempuh oleh semua kendaraan [3].

Langkah-langkah yang harus dikerjakan adalah sebgai beriku [3]:

1. Mengidentifikasi matrik jarak

2. Mengidentifikasikan matrik penghematan (savings matrix)

3. Mengalokasikan toko ke kendaraan atau rute

4. Mengurutkan toko (tujuan) dalam rute yang sudah terdefinisi.

\subsection{Distribution Requirement Planning (DRP)}

Distribution Requirement Planning merupakan aplikasi dari angka logika Material Requirement Planning (MRP). Persediaan Bill of Material (BOM) pada MRP diganti dengan Bill of Distribution (BOD) pada Distribution Requirement Planning (DRP) menggunakan logika Time Phased On Point (TPOP) untuk memerlukan pengadaan kebutuhan pada jaringan. Distribution Requirement Planning didasarkan pada peramalan kebutuhan pada level terendah dalam jaringan tersebut yang akan menentukan kebutuhan persediaan pada level yang lebih tinggi.

\subsection{Metode Saving Matrix}

Metode saving matriks pada hakekatnya adalah metode untuk meminimumkan jarak atau waktu atau ongkos dengan mempertimbangkan kendala-kendala yang ada. Karena disini kita berbicara koordinat tujuan pengiriman maka masuk akal untuk menggunakan jarak sebagai fungsi tujuan. Artinya, kita akan meminimumkan jarak yang ditempuh oleh semua kendaraan [3].

Langkah-langkah yang harus dikerjakan adalah sebgai beriku [3]:

1. Mengidentifikasi matrik jarak

2. Mengidentifikasikan matrik penghematan (savings matrix)

3. Mengalokasikan toko ke kendaraan atau rute

4. Mengurutkan toko (tujuan) dalam rute yang sudah terdefinisi.

\section{Metodelogi Penelitian}

Objek penelitian yang diamati adalah distribusi teh botol sosro kemasan botol plastic dari PT. Sinar Sosro yang berada di Jl. Raya Medan Tanjung Morawa, Kabupaten Deli Serdang menuju distribution center yang ada di wilayah sumatera utara yang didistribusikan dengan menggunakan truk. Data diperoleh melalui pengamatan dan wawancara langsung di PT Sinar Sosro. Adapun yang termasuk data primer dalam penelitian ini yaitu muatan truk dan foto-foto dokumentasi, dan data distribusi, lead time, pemasaran produk, jarak distribution center dan harga bahan bakar minyak. 


\subsection{Metode Analisis}

Adapun model analisis pada penelitian ini adalah sebagai berikut:

1. Menghitung peramalan pemesanan untuk distribution center.

a. Linier, dengan fungsi peramalan:

$$
\begin{aligned}
& Y \mathrm{t}=\mathrm{a}+\mathrm{bt} \\
& \mathrm{a}=\frac{\sum \mathrm{Y}(\mathrm{t})-\mathrm{b} \sum \mathrm{t}}{\mathrm{n}} \\
& b=\frac{n \sum t y-\sum(t) \sum(y)}{n \sum t^{2}-\left(\sum t\right)^{2}}
\end{aligned}
$$

b. Kuadratis, dengan fungsi peramalan:

$$
\begin{aligned}
& \mathrm{Yt}=\frac{\mathrm{a}+\mathrm{bt}+\mathrm{ct} \mathrm{t}^{2}}{n} \\
& b=\frac{\lambda \delta-b \sum t-c \sum t^{2}}{\lambda \beta-\alpha^{2}} \\
& c=\frac{\theta-b \alpha}{\lambda} \\
& \lambda=\left(\sum t^{2}\right)^{2}-n \sum t^{4} \\
& \delta=\sum t \sum Y-n \sum t Y \\
& \theta=\sum t^{2} \sum Y-n \sum t^{2} Y \\
& \alpha=\sum t \sum t^{2}-n \sum t^{3} \\
& \beta=\left(\sum t\right)^{2}-n \sum t^{2}
\end{aligned}
$$

c. Eksponensial, dengan fungsi peramalan:

$$
\begin{aligned}
& \mathrm{Yt}=a \mathrm{e}^{\mathrm{bt}} \\
& \ln a=\frac{\sum \ln Y-b \sum t}{n} \\
& b=\frac{n \sum t \ln Y-\sum t \sum \ln Y}{n \sum t^{2}-\left(\sum t\right)^{2}}
\end{aligned}
$$

Besar kesalahan suatu peramalan dapat dihitung dengan metode yaitu (Makridakis, 1988):

Standard Error of Estimate (SEE)

$$
S E E=\sqrt{\frac{\sum_{t=1}^{m}\left(T_{t}-Y_{t}^{\prime}\right)^{2}}{n-f}}
$$

Dimana :

$\mathrm{f}=$ Nilai derajat kebebasan

$f=1$ (untuk data Konstan)

$f=2$ (untuk data Linier)

$f=2$ (untuk data Eksponensial)

$f=3$ (untuk data Kuadratis)

$f=3$ (untuk data Siklis)

1. Langkah-langkah perhitungan DRP

a. Requirement demand
b. Net requirement $(\mathrm{NR}) \mathrm{T}=(\mathrm{GR}) \mathrm{T}+\mathrm{SS}-(\mathrm{SR}) \mathrm{T}+(\mathrm{POH}) \mathrm{T}-1$
c. Planned order receipt
d. Planned order release
e. Menghitung project on hand

$(\mathrm{POH}) \mathrm{T}=(\mathrm{POH}) \mathrm{T}-1+(\mathrm{SR}) \mathrm{T}+\mathrm{PORT}-(\mathrm{GR}) \mathrm{T}$

2. Melakukan perhitungan saving matrix.

$S(x, y)=J(G, x)+J(G, y)-J(x, y)$

\section{Hasil Dan Pembahasan}

\subsection{Data penelitian}

\begin{tabular}{|c|c|c|c|c|c|c|}
\hline $\begin{array}{l}\text { rincian } \\
\text { biaya }\end{array}$ & DC1 & DC2 & DC3 & DC4 & DC5 & DC6 \\
\hline $\begin{array}{l}\text { Nota } \\
\text { pengiri } \\
\text { man }\end{array}$ & $\begin{array}{l}\text { Rp. } \\
2.50 \\
0\end{array}$ & $\begin{array}{l}\text { Rp. } \\
2.50 \\
0\end{array}$ & $\begin{array}{l}\text { Rp. } \\
2.50 \\
0\end{array}$ & $\begin{array}{l}\text { Rp. } \\
2.50 \\
0\end{array}$ & $\begin{array}{l}\text { Rp. } \\
2.50 \\
0\end{array}$ & $\begin{array}{l}\text { Rp. } \\
2.50 \\
0\end{array}$ \\
\hline $\begin{array}{l}\text { Biaya } \\
\text { supir }\end{array}$ & $\begin{array}{l}\text { Rp. } \\
150 . \\
000\end{array}$ & $\begin{array}{l}\text { Rp. } \\
150 . \\
000\end{array}$ & $\begin{array}{l}\text { Rp. } \\
150 . \\
000\end{array}$ & $\begin{array}{l}\text { Rp. } \\
150 . \\
000\end{array}$ & $\begin{array}{l}\text { Rp. } \\
150 . \\
000\end{array}$ & $\begin{array}{l}\text { Rp. } \\
150 . \\
000\end{array}$ \\
\hline $\begin{array}{l}\text { Biaya } \\
\text { bahan } \\
\text { bakar }\end{array}$ & $\begin{array}{l}\text { Rp. } \\
100 . \\
000\end{array}$ & $\begin{array}{l}\text { Rp. } \\
150 . \\
000\end{array}$ & $\begin{array}{l}\mathrm{Rp} . \\
170 . \\
000\end{array}$ & $\begin{array}{l}\text { Rp. } \\
130 . \\
000\end{array}$ & $\begin{array}{l}\mathrm{Rp} \\
150 . \\
000\end{array}$ & $\begin{array}{l}\text { Rp. } \\
200 . \\
000\end{array}$ \\
\hline $\begin{array}{l}\text { Biaya } \\
\text { bongk } \\
\text { ar } \\
\text { muat }\end{array}$ & $\begin{array}{l}\text { Rp. } \\
75.0 \\
00\end{array}$ & $\begin{array}{l}\text { Rp. } \\
75.0 \\
00\end{array}$ & $\begin{array}{l}\text { Rp. } \\
75.0 \\
00\end{array}$ & $\begin{array}{l}\text { Rp. } \\
75.0 \\
00\end{array}$ & $\begin{array}{l}\text { Rp. } \\
75.0 \\
00\end{array}$ & $\begin{array}{l}\text { Rp. } \\
75.0 \\
00\end{array}$ \\
\hline
\end{tabular}

Data penjualan (distribusi) produk teh botol sosro kemasan botol plastik dari gudang menuju distribution center (DC) selama 8 minggu (November 2020-Desember 2020) dapat dilihat pada Tabel 1 berikut:

Tabel 1 Data Distribusi Produk Teh Botol Sosro Kemasan Botol Plastik

\begin{tabular}{|c|c|c|c|c|c|c|}
\hline $\begin{array}{c}\text { Min } \\
\text { ggu } \\
\text { ke }\end{array}$ & $\begin{array}{c}\text { DC 1 } \\
\text { (cart } \\
\text { on) }\end{array}$ & $\begin{array}{c}\text { DC 2 } \\
\text { (cart } \\
\text { on) }\end{array}$ & $\begin{array}{c}\text { DC 3 } \\
\text { (cart } \\
\text { on) }\end{array}$ & $\begin{array}{c}\text { DC 4 } \\
\text { (cart } \\
\text { on) }\end{array}$ & $\begin{array}{c}\text { DC 5 } \\
\text { (cart } \\
\text { on) }\end{array}$ & $\begin{array}{c}\text { DC 6 } \\
\text { (cart } \\
\text { on) }\end{array}$ \\
\hline 1 & 150 & 130 & 130 & 160 & 150 & 130 \\
\hline 2 & 170 & 120 & 130 & 140 & 160 & 140 \\
\hline 3 & 150 & 130 & 130 & 150 & 170 & 130 \\
\hline 4 & 160 & 140 & 140 & 140 & 150 & 140 \\
\hline 5 & 150 & 130 & 130 & 140 & 150 & 130 \\
\hline 6 & 150 & 120 & 140 & 150 & 150 & 140 \\
\hline 7 & 170 & 140 & 130 & 160 & 160 & 130 \\
\hline 8 & 150 & 130 & 130 & 150 & 150 & 130 \\
\hline Total & 1.250 & 1.040 & 1.060 & 1.190 & 1.240 & 1.070 \\
\hline
\end{tabular}

Sumber: PT. Sinar Sosro

Harga produk teh botol sosro kemasan botol plastik per botolnya adalah Rp.1.400, sehingga harga per carton adalah Rp.16.800. Lead time untuk masing-masing pengiriman menuju DC adalah 1 minggu. Adapun untuk rincian biaya pesan dapat dilihat pada tabel 2 sebagai berikut :

Tabel 2 Rincian Biaya Pesan 


\begin{tabular}{|l|l|l|l|l|l|l|}
\hline Total & Rp. & Rp. & Rp. & Rp. & Rp. & Rp. \\
$\begin{array}{l}\text { Biaya } \\
\text { pengiri } \\
\text { man }\end{array}$ & 327. & 377. & 397. & 357. & 377. & 427. \\
500 & 500 & 500 & 500 & 500 \\
\hline
\end{tabular}

Sumber: PT. Sinar Sosro

Presentase biaya penyimpanan atas suatu produk adalah sebesar $5 \%$ per tahun sehingga nilai biaya simpan perminggu adalah Rp.17,47 per carton.

Dari perhitungan biaya simpan untuk teh botol sosro kemasan botol plastik pada masing-masing distribution center dapat dilihat pada tabel 3 berikut:

Tabel 3 Biaya Simpan Produk Teh Botol Sosro selama 8 minggu

\begin{tabular}{|c|c|}
\hline Wilayah distribusi & Biaya simpan per 8 minggu \\
\hline DC1 & $\mathrm{Rp} 21.840,00$ \\
\hline DC2 & $\mathrm{Rp} 18.170,88$ \\
\hline DC3 & Rp $18.520,32$ \\
\hline DC4 & $\operatorname{Rp} 20.791,68$ \\
\hline DC5 & $\operatorname{Rp} 21.665,28$ \\
\hline DC6 & Rp 18.695,04 \\
\hline Total biaya simpan & Rp $119.683,20$ \\
\hline
\end{tabular}

Sumber: Pengolahan data

Biaya Pengiriman produk Teh Botol Sostro selam 8 minggu dapat dilihat pada tabel 4 berikut :

Tabel 4 Biaya Kirim Produk Teh Botol Sosro selama 8 minggu

\begin{tabular}{|l|l|l|l|}
\hline Tujuan & $\begin{array}{l}\text { Frekuensi } \\
\text { kirim }\end{array}$ & Biaya kirim & $\begin{array}{l}\text { Total biaya } \\
\text { kirim }\end{array}$ \\
\hline DC1 & 8 & Rp. 327.500 & Rp. 2.620 .000 \\
\hline DC2 & 8 & Rp. 377.500 & Rp. 3.020.000 \\
\hline DC3 & 8 & Rp. 397.500 & Rp. 3.180.000 \\
\hline DC4 & 8 & Rp. 357.500 & Rp. 2.860 .000 \\
\hline DC5 & 8 & Rp. 377.500 & Rp. 3.020.000 \\
\hline DC6 & 8 & Rp. 427.500 & Rp. 3.420.000 \\
\hline Total & & Rp. 18.120 .000 \\
\hline
\end{tabular}

Sumber: Pengolahan data

Dari total biaya penyimpanan dan total biaya pengiriman didapat hasil sebagai berikut:

Biaya distribusi = biaya penyimpanan + biaya pengiriman

$$
\begin{aligned}
& =\text { Rp.119.683,20 + Rp.18.120.000 } \\
& =\text { Rp.18.239.683,20 }
\end{aligned}
$$

Berdasarkan hasil peramalan pada tiap-tiap metode (linier, kuadratis, dan eksponensial) maka dapat diketahui niai standard error of estimation (SEE) yang dapat dilihat pada tabel 5 berikut:

Tabel 5 Rekapitulasi Nilai Standard Error of Estimation (SEE)

\begin{tabular}{|c|c|c|}
\hline $\begin{array}{c}\text { Metode } \\
\text { Peramalan }\end{array}$ & $\begin{array}{c}\text { Wilayah } \\
\text { Distribusi }\end{array}$ & $\begin{array}{c}\text { Nilai Standard } \\
\text { Error of } \\
\text { Estimation (SEE) }\end{array}$ \\
\hline Kuadratis & DC1 & 8,3838 \\
\cline { 2 - 3 } & DC2 & 6,6350 \\
\hline
\end{tabular}

\begin{tabular}{|c|c|c|}
\hline \multirow{4}{*}{ Eksponensial } & DC3 & 3,2696 \\
\cline { 2 - 3 } & DC4 & 5,9804 \\
\cline { 2 - 3 } & DC5 & 6,5674 \\
\cline { 2 - 3 } & DC6 & 4,0152 \\
\cline { 2 - 3 } & DC1 & 8,4508 \\
\hline \multirow{4}{*}{ DC2 } & 6,7353 \\
\hline & DC3 & 4,0572 \\
\cline { 2 - 3 } & DC4 & 7,6348 \\
\cline { 2 - 3 } & DC5 & 6,7351 \\
\cline { 2 - 3 } & DC6 & 4,5589 \\
\cline { 2 - 3 } & DC1 & 546,3153 \\
\hline \multirow{7}{*}{ Linier } & DC2 & 458,7994 \\
\cline { 2 - 3 } & DC3 & 465,0177 \\
\cline { 2 - 3 } & DC4 & 522,5558 \\
\cline { 2 - 3 } & DC5 & 538,7921 \\
\cline { 2 - 3 } & DC6 & 466,2723 \\
\hline
\end{tabular}

Sumber: Pengolahan data

Hasil peramalan dengan metode terpilih yaitu kuadratis dapat dilihat pada Tabel 6 berikut :

Tabel 6 Hasil Peramalan Distribution Center

\begin{tabular}{|c|c|c|c|c|c|c|}
\hline $\begin{array}{c}\text { Mingg } \\
\mathrm{u}\end{array}$ & DC1 & DC2 & DC3 & DC4 & DC5 & DC6 \\
\hline 9 & 155 & 131 & 126 & 166 & 148 & 126 \\
\hline 10 & 154 & 131 & 122 & 176 & 145 & 121 \\
\hline 11 & 153 & 130 & 116 & 189 & 142 & 116 \\
\hline 12 & 152 & 129 & 110 & 203 & 138 & 110 \\
\hline 13 & 151 & 128 & 103 & 220 & 133 & 103 \\
\hline 14 & 150 & 127 & 94 & 238 & 128 & 95 \\
\hline 15 & 149 & 125 & 85 & 259 & 123 & 86 \\
\hline 16 & 147 & 123 & 75 & 281 & 117 & 77 \\
\hline Total & 1.21 & 1.02 & 831 & 1.73 & 1.07 & 834 \\
& 2 & 5 & & 1 & 2 & \\
\hline
\end{tabular}

\section{Sumber: Pengolahan data}

Perhitungan Dengan menggunakan metode DRP maka di peroleh hasil sebagai berikut :

1. Perhitungan untuk distribution Center 1 dapat dilihat pada tabel 7 sebagai berikut :

\begin{tabular}{|c|c|c|c|c|c|c|c|c|c|}
\hline Lead time : 1 & Past & \multicolumn{8}{|c|}{ Januari 2020-Februari 2020} \\
\hline $\begin{array}{l}\text { lot size }: \mathrm{FOQ}= \\
170\end{array}$ & & 1 & 2 & 3 & 4 & 5 & 6 & 7 & 8 \\
\hline \begin{tabular}{|l} 
Gross \\
requirements
\end{tabular} & & 155 & 154 & 153 & 152 & 151 & 150 & 149 & 147 \\
\hline $\begin{array}{l}\text { Schedule } \\
\text { Receipt }\end{array}$ & & 170 & & & & & & & \\
\hline Project on hand & & 15 & 31 & 48 & 65 & 84 & 104 & 125 & 148 \\
\hline $\begin{array}{l}\text { Net } \\
\text { Requirements }\end{array}$ & & -15 & 139 & 122 & 105 & 86 & 66 & 45 & 22 \\
\hline $\begin{array}{l}\text { Planned order } \\
\text { receipt }\end{array}$ & & & 170 & 170 & 170 & 170 & 170 & 170 & 170 \\
\hline $\begin{array}{l}\text { Planned order } \\
\text { release }\end{array}$ & & 170 & 170 & 170 & 170 & 170 & 170 & 170 & \\
\hline
\end{tabular}

Tabel 7 Kerangka DRP Distribution Center 1

2. Perhitungan DRP untuk distribution Center 2 dapat dilihat pada tabel 8 berikut:

Tabel 8 Kerangka DRP Distribution Center 2

Copyright (O2020 Department of Industrial Engineering. All right reserved 


\begin{tabular}{|l|c|c|c|c|c|c|c|c|c|}
\hline & $\begin{array}{l}\text { Past } \\
\text { Due }\end{array}$ & \multicolumn{7}{|c|}{ Januari 2020-Februari 2020 } \\
\hline $\begin{array}{l}\text { lot size : FOQ = } \\
170\end{array}$ & 1 & 2 & 3 & 4 & 5 & 6 & 7 & 8 \\
\hline $\begin{array}{l}\text { Gross } \\
\text { requirements }\end{array}$ & 131 & 131 & 130 & 129 & 128 & 127 & 125 & $\begin{array}{c}12 \\
3\end{array}$ \\
\hline $\begin{array}{l}\text { Schedule } \\
\text { Receipt }\end{array}$ & 140 & & & & & & & \\
\hline $\begin{array}{l}\text { Project on } \\
\text { hand }\end{array}$ & 9 & 18 & 27 & 38 & 50 & 63 & 78 & 95 \\
\hline $\begin{array}{l}\text { Net } \\
\text { Requirements }\end{array}$ & -9 & 122 & 112 & 102 & 90 & 77 & 62 & 45 \\
\hline $\begin{array}{l}\text { Planned order } \\
\text { receipt }\end{array}$ & & 140 & 140 & 140 & 140 & 140 & 140 & 140 & 0 \\
\hline $\begin{array}{l}\text { Planned order } \\
\text { release }\end{array}$ & & 140 & 140 & 140 & 140 & 140 & 14 \\
\hline
\end{tabular}

3. Perhitungan DRP untuk distribution Center 3 dapat dilihat pada tabel 9 berikut:

Tabel 9 Kerangka DRP Distribution Center 3

\begin{tabular}{|l|r|r|r|r|r|r|r|r|r|}
\hline Lead time : 1 & $\begin{array}{r}\text { Past } \\
\text { Due }\end{array}$ & \multicolumn{7}{|c|}{ Januari 2020-Februari 2020} \\
\hline $\begin{array}{l}\text { lot size : FOQ = } \\
130\end{array}$ & & 1 & 2 & 3 & 4 & 5 & 6 & 7 & 8 \\
\hline $\begin{array}{l}\text { Gross } \\
\text { requirements }\end{array}$ & 126 & 122 & 116 & 110 & 103 & 94 & 85 & 75 \\
\hline Schedule Receipt & 130 & & & & & & & \\
\hline Project on hand & & 4 & 12 & 25 & 45 & 73 & 108 & 23 & 79 \\
\hline $\begin{array}{l}\text { Net } \\
\text { Requirements }\end{array}$ & -4 & 118 & 105 & 85 & 57 & 22 & -23 & 51 \\
\hline $\begin{array}{l}\text { Planned order } \\
\text { receipt }\end{array}$ & & 130 & 130 & 130 & 130 & 130 & & & 130 \\
\hline $\begin{array}{l}\text { Planned order } \\
\text { release }\end{array}$ & & 130 & 130 & 130 & 130 & & 130 \\
\hline
\end{tabular}

4. Perhitungan DRP untuk distribution Center 4 dapat dilihat pada tabel 10 berikut:

Tabel 10 Kerangka DRP Distribution Center 4

\begin{tabular}{|l|c|r|r|r|r|r|r|r|r|}
\hline $\begin{array}{l}\text { Lead time : } \\
1\end{array}$ & $\begin{array}{l}\text { Past } \\
\text { Due }\end{array}$ & \multicolumn{7}{|c|}{ Januari 2020-Februari 2020} \\
\hline $\begin{array}{l}\text { lot size : FOQ } \\
=300\end{array}$ & & 1 & 2 & 3 & 4 & 5 & 6 & 7 & 8 \\
\hline $\begin{array}{l}\text { Gross } \\
\text { requirements }\end{array}$ & 166 & 176 & 189 & 203 & 220 & 238 & 259 & 281 \\
\hline $\begin{array}{l}\text { Schedule } \\
\text { Receipt }\end{array}$ & 300 & 134 & 258 & 69 & 166 & 246 & 8 & 49 & 68 \\
\hline $\begin{array}{l}\text { Project on hand } \\
\text { Net } \\
\text { Requirements }\end{array}$ & -134 & 42 & -69 & 134 & 54 & -8 & 251 & 232 \\
\hline $\begin{array}{l}\text { Planned order } \\
\text { receipt }\end{array}$ & & 300 & 0 & 300 & 300 & 0 & 300 & 300 & \\
\hline $\begin{array}{l}\text { Planned order } \\
\text { release }\end{array}$ & & 300 & & 300 & 300 & & 300 & 300 \\
\hline
\end{tabular}

5. Perhitungan DRP untuk distribution Center 5 dapat dilihat pada tabel 11 berikut:

Tabel 11 Kerangka DRP Distribution Center 5

\begin{tabular}{|l|c|c|c|c|c|c|c|c|c|}
\hline Lead time : 1 & $\begin{array}{l}\text { Past } \\
\text { Due }\end{array}$ & \multicolumn{7}{|c|}{ Januari 2020-Februari 2020} \\
\hline $\begin{array}{l}\text { lot size : FOQ = } \\
150\end{array}$ & 1 & 2 & 3 & 4 & 5 & 6 & 7 & 8 \\
\hline $\begin{array}{l}\text { Gross } \\
\text { requirements }\end{array}$ & & 148 & 145 & 142 & 138 & 133 & 128 & 123 & 117 \\
\hline $\begin{array}{l}\text { Schedule } \\
\text { Receipt }\end{array}$ & 150 & & & & & & & \\
\hline $\begin{array}{l}\text { Project on } \\
\text { hand }\end{array}$ & & 2 & 7 & 15 & 28 & 45 & 67 & 94 & 128 \\
\hline
\end{tabular}

\begin{tabular}{|l|c|c|c|c|c|c|c|c|c|}
\hline $\begin{array}{l}\text { Net } \\
\text { Requirements }\end{array}$ & -2 & 143 & 135 & 122 & 105 & 83 & 56 & 22 \\
\hline $\begin{array}{l}\text { Planned order } \\
\text { receipt }\end{array}$ & & & 150 & 150 & 150 & 150 & 150 & 150 & 150 \\
\hline $\begin{array}{l}\text { Planned order } \\
\text { release }\end{array}$ & 150 & 150 & 150 & 150 & 150 & 150 & 150 & \\
\hline
\end{tabular}

6. Perhitungan kerangka DRP untuk distribution Center 6 dapat dilihat pada tabel 12 berikut:

Tabel 12 Kerangka DRP Distribution Center 6

\begin{tabular}{|l|c|c|c|c|c|c|c|c|}
\hline Lead time : 1 & $\begin{array}{l}\text { Past } \\
\text { Due }\end{array}$ & \multicolumn{7}{|c|}{ Januari 2020-Februari 2020} \\
\hline $\begin{array}{l}\text { lot size : FOQ }= \\
130\end{array}$ & 1 & 2 & 3 & 4 & 5 & 6 & 7 & 8 \\
\hline $\begin{array}{l}\text { Gross } \\
\text { requirements }\end{array}$ & 126 & 121 & 116 & 110 & 103 & 95 & 86 & 77 \\
\hline $\begin{array}{l}\text { Schedule } \\
\text { Receipt }\end{array}$ & 130 & & & & & & & \\
\hline Project on hand & 4 & 13 & 27 & 47 & 74 & 109 & 23 & 76 \\
\hline $\begin{array}{l}\text { Net } \\
\text { Requirements }\end{array}$ & -4 & 117 & 103 & 83 & 56 & 21 & -23 & 54 \\
\hline $\begin{array}{l}\text { Planned order } \\
\text { receipt }\end{array}$ & & 130 & 130 & 130 & 130 & 130 & & 130 \\
\hline $\begin{array}{l}\text { Planned order } \\
\text { release }\end{array}$ & 130 & 130 & 130 & 130 & 130 & 0 & 130 & \\
\hline
\end{tabular}

Berdasarkan metode DRP diatas maka didapat biaya distribusi untuk masing-masing DC sebagai berikut:

Tabel 13 Biaya Distribusi untuk Setiap Distribution

Center

\begin{tabular}{|c|c|}
\hline Wilayah Distribusi & Biaya Distribusi \\
\hline DC1 & Rp. 2.303.356 \\
\hline DC2 & Rp. 2.649.114 \\
\hline DC3 & Rp. 2.391 .439 \\
\hline DC4 & Rp. 1.804 .971 \\
\hline DC5 & Rp. 2.649.213 \\
\hline DC6 & Rp. 2.571.514 \\
\hline Total & Rp. 14.369 .607 \\
\hline
\end{tabular}

Sumber: Pengolahan data

Untuk mengetahui peenghematan biaya pengiriman \& dari gudang menuju distribution center (DC) dapat dilakukan dengan cara penghematan jarak (saving 1matrix), dengan data DC dapat dilihat pada tabel 14 berikut:

8 Tabel 14 Jarak dari Gudang Menuju Distribution Center

\begin{tabular}{|c|c|c|}
\hline $\begin{array}{c}\text { Wilayah } \\
\text { Distribusi }\end{array}$ & Biaya Distribusi & $\begin{array}{c}\text { Jarak } \\
(\mathrm{km})\end{array}$ \\
\hline DC1 & Jl. Menteng VII, Medan & 9,3 \\
\hline DC2 & Jl. Panglima Denai, Amplas & 15,1 \\
\hline DC3 & Jl. Halat, Medan & 18,3 \\
\hline DC4 & Jl. Ampera, Medan & 22 \\
\hline DC5 & J. Letjen Suprapto, Medan & 23,4 \\
\hline DC6 & Jl. HM Joni, Medan & 19 \\
\hline
\end{tabular}

Sumber: PT. Sinar Sosro

Adapun jarak dari Gudang ke masing-masing DC dapat dilihat pada tabel 15 sebagai berikut:

Tabel 15 Matriks Jarak

\begin{tabular}{|l|l|r|r|r|r|r|r|r|}
\hline $\mathrm{N}$ & Lokasi & gudang & 1 & 2 & 3 & 4 & 5 & 6 \\
\hline & Gudang & 0 & & & & & & \\
\hline 1 & DC1 & 9,3 & 0,0 & & & & & \\
\hline
\end{tabular}




\begin{tabular}{|l|l|l|c|c|c|c|c|c|}
\hline 2 & DC2 & 15,1 & 5,8 & 0,0 & & & & \\
\hline 3 & DC3 & 18,3 & 11,0 & 3,3 & 0,0 & & & \\
\hline 4 & DC4 & 22,0 & 13,0 & 4,2 & 3,7 & 0,0 & & \\
\hline 5 & DC5 & 23,4 & 14,4 & 8,5 & 5,4 & 1,4 & 0,0 & \\
\hline 6 & DC6 & 19,0 & 13,0 & 7,1 & 1,7 & 4,0 & 4,4 & 0,0 \\
\hline
\end{tabular}

\section{Sumber: PT. Sinar Sosro}

Dengan rumus saving matrix maka dapat dicari matrix penghematan antar konsumen dengan menggunakan jarak yang ada pada tabel 16 dan berikut adalah hasil perhitungan saving matrix:

Tabel 16 Saving Matrix

\begin{tabular}{|c|l|r|r|r|r|r|r|}
\hline No & Lokasi & 1 & 2 & 3 & 4 & 5 & 6 \\
\hline 1 & DC1 & 0,0 & & & & & \\
\hline 2 & DC2 & 18,6 & 0,0 & & & & \\
\hline 3 & DC3 & 16,6 & 30,1 & 0,0 & & & \\
\hline 4 & DC4 & 18,3 & 32,9 & 36,6 & 0,0 & & \\
\hline 5 & DC5 & 18,3 & 30,0 & 36,3 & 44,0 & 0,0 & \\
\hline 6 & DC6 & 15,3 & 27,0 & 35,6 & 37,0 & 38,0 & 0,0 \\
\hline
\end{tabular}

Sumber: Pengolahan data

Perhitungan rute dengan seving Matrix, hasil perhitungan dapat dilihat pada tabel 17 berikut :

Tabel 17 Rute dengan Saving Matrix

\begin{tabular}{|c|c|c|c|c|}
\hline $\begin{array}{c}\text { Urutan } \\
\text { penghematan }\end{array}$ & Tujuan & $\begin{array}{c}\text { Saving } \\
\text { matriks }\end{array}$ & $\begin{array}{c}\text { Total } \\
\text { muatan }\end{array}$ & Keterangan \\
\hline tertinggi ke 1 & 4 ke 5 & 44 & 450 & Tidak layak \\
\hline tertinggi ke 2 & 5 ke 6 & 38 & 280 & Layak \\
\hline tertinggi ke 3 & 3 ke 4 & 36,6 & 430 & Tidak layak \\
\hline tertinggi ke 4 & 2 ke 4 & 32,9 & 440 & tidak layak \\
\hline tertinggi ke 5 & 2 ke 3 & 30,1 & 270 & Layak \\
\hline tertinggi ke 6 & 1 & 18,6 & 170 & Layak \\
\hline tertinggi ke 7 & 4 & 18,3 & 300 & Layak \\
\hline
\end{tabular}

Sumber: Pengolahan data

Maka dari tabel diatas diperoleh hasil rute usulan seperti dapat dilihat pada tabel 18 sebagai berikut:

Tabel 18 Rute Usulan menggunakan Saving Matrix

\begin{tabular}{|c|c|c|c|c|}
\hline No & Rute Usulan & Jarak tempuh & $\begin{array}{l}\text { Total } \\
(\mathrm{km})\end{array}$ & $\begin{array}{l}\text { Kapasitas } \\
\text { (Carton) }\end{array}$ \\
\hline 1 & G-DC5-DC6-G & $23,4+4,4+19$ & 46,8 & 280 \\
\hline 2 & G-DC2-DC3-G & $15,1+3,3+18,3$ & 36,7 & 270 \\
\hline 3 & G-DC1-G & $9,3+9,3$ & 18,6 & 170 \\
\hline 4 & G-DC4-G & $22+22$ & 44 & 300 \\
\hline \multicolumn{3}{|c|}{ Total } & 146,1 & 1.020 \\
\hline
\end{tabular}

Sumber: Pengolahan data

\subsection{Pembahasan}

Setelah melakukan biaya pengadaan untuk 8 periode selanjutnya dengan dengan menggunakan metode DRP, maka didapat selisih sebagai berikut:

Selisih = Biaya distribusi perusahaan-biaya distribusi DRP

$=$ Rp.18.239.683,20 - Rp 14.369.607

$=$ Rp. 3.870 .076

efisiensi biaya $=$

biaya distribusi awal - biaya distribusi usulan biaya distribusi awal

Maka, efisiensi biaya yang diperoleh menggunakan metode saving matrix adalah sebagai berikut: efisiensi biaya $=$

\section{Rp.18.239.683,20-Rp. 14.369.607 Rp.18.239.683,20 $\times 100 \%$

$$
=21,218 \%
$$

Pada rute usulan total jarak tempuh yang dilalui sebesar $146,1 \mathrm{~km}$ dan pada rute awal total jarak yang dilalui sebesar 214,2 km dengan selisih jarak rute usulan dan rute awal sebesar $68,1 \mathrm{~km}$.

Dengan menggunakan jarak tempuh usulan maka dapat dihitung efisiensi jarak dengan cara:

efisiensi jarak $=\frac{\text { Rute Awal }- \text { Rute Usulan }}{\text { Rute Awal }} \times 100 \%$

Maka, efisiensi jarak yang diperoleh menggunakan metode saving matrix adalah sebagai berikut:

$$
\text { efisiensi jarak }=\frac{214,2-146,1}{214,2} \times 100 \%
$$

$$
=31,79 \%
$$

Uang bahan bakar yang dikeluarkan untuk jarak tempuh $214,2 \mathrm{~km}$ yaitu sebesar Rp.900.000. Maka dapat diasumsikan biaya bahan bakar adalah Rp. 4201,68/km. Uang biaya bahan bakar yang harus dikeluarkan dengan menggunakan metode perusahaan yaitu:

Uang BBM awal $=\mathrm{Rp} .900 .000 \times 8$ trip pengiriman

Uang BBM awal $=$ Rp. 7.200.000

Maka uang bahan bakar yang harus dikeluarkan untuk jarak tempuh setelah dilakukan perhitungan saving matrix adalah sebagai berikut:

Uang BBM saving matrix $=\mathrm{Rp} .4201,68 \times 146,1 \mathrm{~km} \times 8$ trip Uang BBM saving matrix $=$ Rp. 4.910.923,58

Maka, efisiensi biaya saving matrix adalah sebagai berikut:

efisiensi biaya $=$

$\frac{\text { uang bbm awal-uang bbm saving matrix }}{\text { uang bbm awal }} \times 100 \%$

efisiensi biaya $=$

Rp. 7.200.000-Rp. 4.910.923,58

$$
\begin{gathered}
\text { Rp. } 7.200 .000=31,79 \% \\
=100 \%
\end{gathered}
$$

\section{Kesimpulan}

Berdasarkan hasil perhitungan yang telah dilakukan sebelumnya maka didapatkan kesimpulan sebagai berikut:

1. Distribusi teh botol sosro kemasan botol plastik yang efektif dengan menggunakan metode DRP selama 8 periode dari PT. Sinar Sosro menuju Distribution Center yaitu untuk DC 1 sebanyak 1.212 carton, DC 2 sebanyak 1.025 carton, DC 3 sebanyak 831 carton, DC 4 sebanyak 1.731 carton, DC 5 sebanyak 1.072 carton, dan DC 6 sebanyak 834 carton.

2. Adapun output DRP yang optimal pada PT. Sinar 
Sosro yaitu DC 1 memiliki total Gross requirements sebesar 1.212 carton, Project on hand sebesar 621 carton, DC 2 memiliki total Gross requirements sebesar 1.025 carton, Project on hand sebesar 379 carton, DC 3 memiliki total Gross requirements sebesar 831 carton, Project on hand sebesar 369 carton, DC 4 memiliki total Gross requirements sebesar 1.731 carton, Project on hand sebesar 1.000 carton, DC 5 memiliki total Gross requirements sebesar 1.072 carton, Project on hand sebesar 384 carton, dan DC 6 memiliki total Gross requirements sebesar 834 carton, Project on hand sebesar 373 carton.

3. Jumlah rute awal yang digunakan oleh perusahaan sebanyak 6 rute dengan total jarak tempuh sebesar $214,2 \mathrm{~km}$ dengan biaya bahan bakar sebesar Rp. $900.000,00$, sedangkan pada rute usulan menghasilkan 4 rute dengan jarak total rute usulan yaitu sebesar 146,1 km dan biaya bahan bakar sebesar Rp. 286.134,00. Penerapan rute usulan ini dapat menghasilkan efisiensi jarak sebesar 31,79\% .

\section{Daftar Pustaka}

[1] Abdillah, Adib Fahrozi. 2009. Perencanaan Dan Penjadwalan Aktivitas Distribusi Hasil Perikanan Dengan Menggunakan Distribution Requirement Planning (DRP).

[2] Armstrong, J., \& Fildes, R. (2006). Making Progress in Forecasting. International Journal of Forecasting, 22, 433-411.

[3] Harry, S., \& Syamsudin, N. (2011). Penerapan Supply Chain Management pada Proses Management Distribusi dan Transportasi untuk Meminimasi Waktu dan Biaya Pengiriman. Jurnal Poros Teknik.Vol. 3, No. 1., 4.

[4] Heizer, J., \& Render, B. (2005). Operations Management. Jakarta: Salemba Empat.

[5] Indiyanto, R. (2008). Perencanaan Dan Pengendalian Produksi (Pdf). Surabaya: Yayasan Humaniora.

[6] Purnomo, A. (2010). Penentuan Rute Pengiriman dan Biaya Transportasi dengan Menggunakan Metode Clark and Wright Saving Heuristic (Studi Kasus di PT Teh Botol Sosro Bandung). Jurnal Universitas Pasundan Bandung, Vol. 01, No. 02., 4.

[7] Senator, N. B. (2006). Sistem Inventori. Bandung: ITB.

[8] Suparjo. 2017. Metode Saving Matrix Sebagai Metode Alternatif untuk Efisiensi Biaya Distribusii. Media Ekonomi dan Manajemen vol. 32 no. 2. (Studi Empirik Pada Perusahaan Angkutan Kayu Gelondongan Di Jawa Tengah) 